Research Paper

\title{
Meta-Analysis of the Association of the Rs2234693 and Rs9340799 Polymorphisms of Estrogen Receptor Alpha Gene with Coronary Heart Disease Risk in Chinese Han Population
}

\author{
Chuan-Dong Wei ${ }^{1,2,3}$, Hong-Yun Zheng ${ }^{1}$, Wei $\mathrm{Wu}^{1}{ }^{1}$, Wen Dai ${ }^{2}$, Yong-Qing Tong ${ }^{1}$, Ming Wang ${ }^{1}$ and \\ Yan $\mathrm{Li}^{1,2}{ }^{\otimes}$ \\ 1. Center for Clinical Molecular Diagnosis, Renmin Hospital of Wuhan University, Wuhan 430060, Hubei, China; \\ 2. Department of Clinical Laboratory, Renmin Hospital of Wuhan University, Wuhan 430060, Hubei, China; \\ 3. Department of Clinical Laboratory, Affiliated Hospital of You Jiang Medical University for Nationalities, Baise 533000, Guangxi, China.
}

$\square$ Corresponding author: Yan Li; Department of Clinical Laboratory, Renmin Hospital of Wuhan University, 99 Ziyang Road, District of Wuchang Wuhan 430060, Hubei, China. Email: yanlitf@yahoo.com.cn.

(C) Ivyspring International Publisher. This is an open-access article distributed under the terms of the Creative Commons License (http://creativecommons.org/ licenses/by-nc-nd/3.0/). Reproduction is permitted for personal, noncommercial use, provided that the article is in whole, unmodified, and properly cited.

Received: 2012.09.17; Accepted: 2013.01.25; Published: 2013.03.02

\begin{abstract}
Objective: The association between a common variant of the ESRI gene rs2234693 and rs9340799 polymorphisms with coronary heart disease (CHD) have been reported, but the available data on this relationship are inconsistent. A meta-analysis was performed to quantitative analysis the association of ESRI gene polymorphisms and CHD risk using previous case-control studies in Chinese Han population.

Methods: Several electronic databases were searched for relevant articles up to August 2012. After data collection, a meta-analysis was performed to assess heterogeneity, combine results and evaluate variations. Different effect models were used according to the difference in heterogeneity. Sensitivity analysis was assessed by omitting one study at a time. Publication bias was examined using Begg's funnel plot and Egger's linear regression test.

Results: Ten studies covering 3400 subjects on rs2234693 and rs 9340799 polymorphisms in the ESRI gene with CHD risk was included in this meta-analysis. For rs 2234693 polymorphism, ten studies were combined to the meta-analysis. A significantly increased CHD risk was found in a dominant model $(O R=1.35,955 \mathrm{Cl}=1.01-1.81, P=0.05)$, recessive model $(O R=1.40,95 \%$ $\mathrm{Cl}=1.15-\mathrm{I} .69, P=0.0007)$, and additive model $(\mathrm{OR}=1.67,95 \% \mathrm{Cl}=1.19-2.34, P=0.003)$. Subgroup for male but not for female showed that the CC genotype could increase the risk of CHD compared with TT and TC genotype in Chinese Han population. Concerning rs 9340799 polymorphism, eight studies were combined to the meta-analysis. And no evidence of significant association with CHD risk was found in all genetic models.

Conclusion: Our meta-analysis of 10 studies involving Chinese Han population suggests that the CC genotype of the ESRI rs2234693 polymorphism is significantly associated with an increased risk of CHD in males only. There was no evidence however, of a significant association between the ESRI rs9340799 polymorphism and CHD risk.
\end{abstract}

Key words: Estrogen receptor alpha gene, Coronary heart disease, Single nucleotide polymorphisms, Meta-analysis. 


\section{Introduction}

Coronary heart disease (CHD) is a main public health problem around the world [1]. It is well known that CHD is associated closely with inherited factors, environmental factors and their interactions, and the genetic factors play important roles in the pathogenesis of CHD [2]. Previous study shown that the younger age and independently of differences in lifestyle, women are at lower risk for CHD than men [3], however, cardiovascular morbidity and mortality sharply increase after the onset of menopause [4]. Epidemiological and laboratory studies have demonstrated that estrogen has a protective effect on the cardiovascular system [5, 6]. Estrogen exert their effects through banding and activating estrogen receptors (ERs) that influence multiple organ systems in both men and women, including a number of human cancers (breast, ovarian, colorectal, prostate, and endometrial), endometriosis, fibroids, and cardiovascular disease [7].

There are two main forms of ER exist, ER- $\alpha$ and ER- $\beta$, which are encoded by separate genes, ESR1 and ESR2, respectively. Each receptor has distinct tissue expression patterns, post-translational modifications, and cellular localization in normal and disease states. The ERs are classical hormone nuclear receptors and members of the nuclear receptor super family having the functional structural domains A-F [8-10]. ESR1 is a main mediator effect of estrogen, and plays an important role in vascular wall physiology and function $[11,12]$. Existence or activation of the ESR1 is required for the observed cardioprotective effects of estrogen from ischemia-reperfusion myocardial injury [13, 14]. Researches also indicated that single nucleotide polymorphisms of ESR1 might influence the expression of ESR1 and affect the function of estrogen on CHD $[15,16]$. The two most frequently studies polymorphisms in ESR1, often identified by their restriction endonucleases of PvuII and XbaI, are located in the first intron of the ESR1 gene, 397 and 351 base pairs upstream of exon 2, respectively. The PvuII restriction site polymorphism involves a rs2234693 (397T>C), while the $\mathrm{XbaI}$ restriction site polymorphism involves a rs9340799 (351A>G).

Recently, various studies on the association between ESR1 rs2334693 and rs9340799 polymorphisms and CHD risk among different populations including Chinese Han population [17-20]. However, with relatively small sample sizes, and in Chinese Han population these former studies provided limited information and could not draw a convincing conclusion. Therefore, in this study, a meta-analysis was performed on previous reports to assess the association between the ESR1 gene rs2234693 and rs9340799 polymorphisms and the risk of CHD among Chinese Han population.

\section{Research design and methods}

\section{Search strategy}

The electronic databases of PubMed, EMBASE, Chinese National Knowledge Infrastructure (CNKI) and Chinese Wan Fang were searched for eligible articles. The search strategy to identify all potential studies involved using combinations of 'estrogen receptor gene', or 'ER', and 'polymorphism', or 'gene variant' and 'coronary heart disease' or 'ischemic heart disease' or 'myocardial infarction' and China/Chinese. The publication language was limited to English or Chinese. The literature search was updated on 31 August 2012; we used no lower date limit. When study recruitment overlapped by more than $30 \%$ in two or more articles by the same author(s), the one with the largest population of participants or the most recent one was used in this meta-analysis. References of retrieved articles were also screened. The study of systematic review was conducted according to the Meta-analysis of Observational Studies in Epidemiology (MOOSE) guidelines [21].

\section{Eligibility criteria}

Eligible studies included case-control that investigating the association ESR1 rs2234693 and rs9340799 polymorphisms with CHD risk among the Chinese Han population. The included studies have to meet the following criteria: (1) the study provides cases of CHD and control group; (2) the study provides information on the genotype frequency and the use of validated molecular methods for genotyping; (3) the genotype distribution of the control groups subject to genetic equilibrium in the Hardy-Weinberg (HW) and (4) the studies were providing sufficient data for estimating an odds ratio (OR) with 95\% confidence interval (CI). The diagnosis of the case group was according to the WHO criteria for CHD (stenosis $\geq 50 \%$ of the diameter in at least one major coronary artery based on computer-assisted assessments) [22] and was confirmed by coronary artery angiography. All control subjects were judged to without of CHD based on patient history, clinical examination and electrocardiography.

\section{Data extraction}

Data was carefully extracted from all acceptable publications independently by two of reviewers (Wei and Zheng) according to the eligible criteria listed above. Disagreements were resolved by consensus 
and by consulting a third author. The following data were collected by each study: first author, year of publication, region of origin, ethnicity, study design, definition and total number of cases and controls, sex distribution and mean age, genotyping methods, genotype, allele distributions (where data were not given, they were calculated from the corresponding genotype frequencies of the case and control groups) and the $P$-value of Hardy-Weinberg equilibrium (HWE) test in the control population.

\section{Statistical analysis}

Data analysis was performed according to the method reference from [23]. The $P$-value of HWE in the control group of each study should be evaluated, because the results of transmission-disequilibrium analysis could be biased if there is a deviation from HWE. The $P$-value of HWE was tested by using a chi-square test, and the study deviation from HWE was excluded from our meta- analysis.

The association ESR1 rs2234693 and rs9340799 polymorphisms with $\mathrm{CHD}$ risk was estimated by calculating a pooled odds ratio (OR) and corresponding 95\% confidence intervals (CIs) under a dominant model, a recessive model, an additive model, co-dominant model and allele contrast, respectively. The pooled OR with $95 \%$ CI in each case-control study was used to assess the strength of association. The significance of the pooled OR was determined by a $\mathrm{Z}$ test $(P \leq 0.05$ was considered statistically significant). The between-study heterogeneity across all eligible comparisons was assessed using the $Q$ statistic, and the $\mathrm{I}^{2}$ statistic was used to estimate heterogeneity quantitatively [24]. Heterogeneity was considered significant at a $P$-value of $\leq 0.10[25,26]$, and which also was used to select random effect model or fixed effect model to quantitative analysis. A random effect model was performed when heterogeneity was present.

Sensitivity analysis was performed to assess the stability of the results by removing one study at a time to evaluate the stability of the results of meta-analysis. Publication bias was assessed qualitatively by constructing funnel plots and quantitatively using Begg and Egger's linear regression test [27, 28].

Data were analyzed using Review Manager 5.0 software (available from The Cochrane Collaboration at http://www.cochrane.org) and stata software, version 11.2 (STATA Corp., College Station, TX, USA). Two-sided of the $P$-values less than 0.05 was considered statistically significant, except for tests of heterogeneity where a level of 0.10 was used.

\section{Results}

\section{Studies Characteristics}

A total of 10 eligible studies were identified based on our criteria [19, 29-37]. The detailed flow chart of the inclusion/exclusion process is presented in Fig. 1. PCR-RFLP or TaqMan was used for examining the mutations of ESR1 rs2234693 and rs9340799 polymorphisms. All of these studies included were agreements with HWE in controls. The characteristics of the included studies for ESR1 rs2234693 and rs9340799 polymorphisms are listed in Table $\mathbf{1}$ and Table 2.

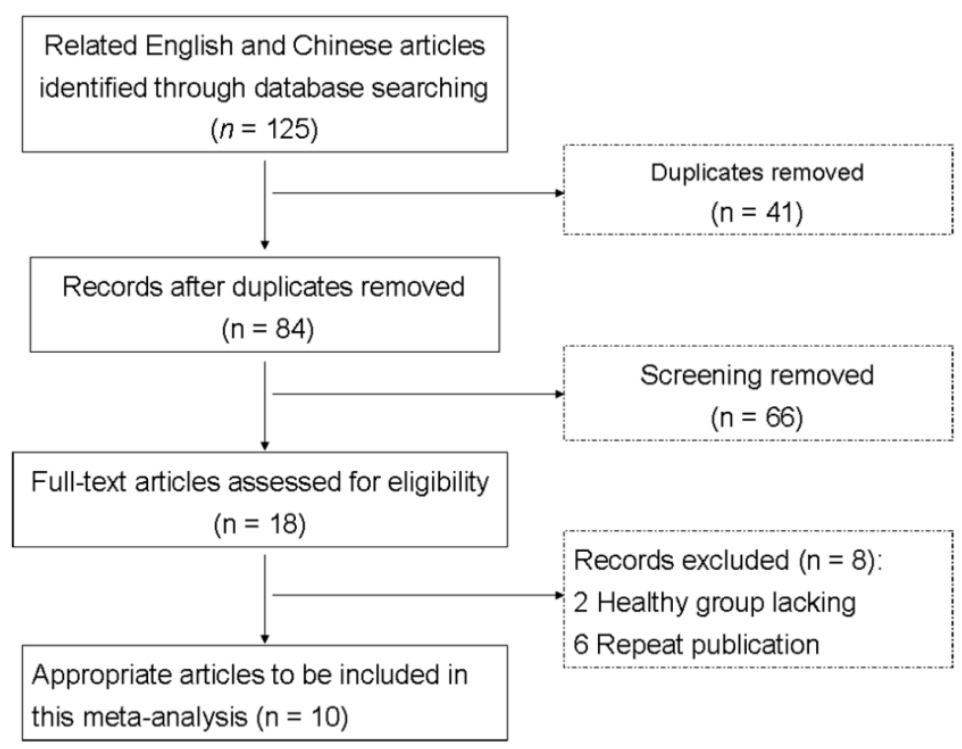

Fig I. Flow diagram of the selection of eligible studies. 
Table I. Characteristics of the studies rs 2234693 polymorphism included in the meta-analysis.

\begin{tabular}{|c|c|c|c|c|c|c|c|c|c|c|c|c|c|c|c|c|c|c|}
\hline \multirow[t]{2}{*}{$\begin{array}{l}\text { First author and } \\
\text { publication year }\end{array}$} & \multirow[t]{2}{*}{ Region } & \multicolumn{2}{|c|}{ Gender (M/F) } & \multicolumn{2}{|c|}{ Mean age (year) } & \multicolumn{2}{|c|}{ Sample size } & \multicolumn{3}{|c|}{$\begin{array}{l}\text { Genotype fre- } \\
\text { quency in cases }\end{array}$} & \multicolumn{2}{|c|}{$\begin{array}{l}\text { Alleles, } n \\
\text { in cases }\end{array}$} & \multicolumn{3}{|c|}{$\begin{array}{l}\text { Genotype } \\
\text { frequency in } \\
\text { controls }\end{array}$} & \multicolumn{2}{|c|}{$\begin{array}{l}\text { Alleles, } n \\
\text { in control }\end{array}$} & \multirow[t]{2}{*}{$\begin{array}{l}\mathrm{P} \\
\mathrm{HW} \\
\mathrm{E}\end{array}$} \\
\hline & & Cases & Controls & Cases & Controls & Cases & $\begin{array}{l}\text { Con- } \\
\text { trols }\end{array}$ & TT & TC & $\mathrm{CC}$ & $\mathrm{T}$ & $\mathrm{C}$ & $\mathrm{TT}$ & TC & $\begin{array}{l}\mathrm{C} \\
\mathrm{C}\end{array}$ & $\mathrm{T}$ & $\mathrm{C}$ & \\
\hline Zheng, 2001 [29] & $\begin{array}{l}\text { Guang } \\
\text { dong }\end{array}$ & $\begin{array}{l}70 / \\
14\end{array}$ & $\begin{array}{l}48 / \\
13\end{array}$ & $61.82 \pm 10.61$ & $59.92 \pm 9.43$ & 84 & 61 & 14 & 48 & 22 & 76 & 92 & 25 & 27 & 9 & 77 & 45 & 0.7 \\
\hline Guo, 2002 [30] & $\begin{array}{l}\text { Guang } \\
\text { dong }\end{array}$ & $\begin{array}{l}58 / \\
14\end{array}$ & $\begin{array}{l}41 / \\
12\end{array}$ & $65.1 \pm 5.6$ & $64.3+4.2$ & 72 & 53 & 10 & 42 & 20 & 62 & 82 & 23 & 23 & 7 & 69 & 37 & 0.74 \\
\hline Huang, 2002 [31] & Hubei & $\begin{array}{l}81 / \\
54\end{array}$ & $\begin{array}{l}50 / \\
68\end{array}$ & $\begin{array}{l}\text { No men- } \\
\text { tioned }\end{array}$ & $\begin{array}{l}\text { No men- } \\
\text { tioned }\end{array}$ & 135 & 118 & 80 & 41 & 14 & 201 & 69 & 51 & 54 & 13 & 156 & 80 & 0.82 \\
\hline Zheng, 2002 [32] & Hebei & $\begin{array}{l}0 / \\
51\end{array}$ & $\begin{array}{l}0 / \\
54\end{array}$ & $64.21 \pm 9.75$ & $62.05 \pm 7.8$ & 51 & 54 & 9 & 35 & 7 & 53 & 49 & 18 & 30 & 6 & 66 & 42 & 0.21 \\
\hline Cheng, 2006 [33] & Tianjin & $105 / 95$ & $\begin{array}{l}98 / \\
92\end{array}$ & $56.5 \pm 0.4$ & $52.4 \pm 0.6$ & 200 & 190 & 65 & 92 & 43 & 222 & 178 & 67 & 85 & 38 & 219 & 161 & 0.25 \\
\hline Li, 2006 [34] & Tianjin & $\begin{array}{l}0 / \\
165\end{array}$ & $0 / 80$ & $61.7 \pm 8.2$ & $59.9 \pm 7.7$ & 165 & 80 & 33 & 88 & 44 & 154 & 176 & 21 & 36 & 23 & 78 & 82 & 0.37 \\
\hline $\mathrm{Xu}, 2008$ [19] & $\begin{array}{l}\text { Jiang- } \\
\text { su }\end{array}$ & $\begin{array}{l}94 / \\
116\end{array}$ & $\begin{array}{l}89 / \\
85\end{array}$ & $56.0 \pm 7.3$ & $55.0 \pm 8.6$ & 210 & 174 & 92 & 88 & 30 & 272 & 148 & 82 & 78 & 14 & 242 & 106 & 0.44 \\
\hline Tang, 2008 [35] & Hubei & $161 / 0$ & $158 / 0$ & $61.4 \pm 8.1$ & $60.9 \pm 6.4$ & 161 & 158 & 48 & 76 & 37 & 172 & 150 & 46 & 79 & 33 & 171 & 145 & 0.93 \\
\hline Jin, 2010 [36] & $\begin{array}{l}\text { Guang } \\
\text { dong }\end{array}$ & $169 / 67$ & $\begin{array}{l}75 / \\
42\end{array}$ & $64.0 \pm 11.0$ & $62.0 \pm 11.0$ & 236 & 117 & 84 & 105 & 47 & 199 & 273 & 49 & 57 & 11 & 79 & 155 & 0.33 \\
\hline Shen, 2012 [37] & $\begin{array}{l}\text { Chong- } \\
\text { qing }\end{array}$ & $\begin{array}{l}289 / 25 \\
0\end{array}$ & $286 / 253$ & $57.3 \pm 7.2$ & $56.4 \pm 9.1$ & 539 & 539 & 245 & 226 & 68 & 716 & 362 & 274 & 217 & 48 & 765 & 313 & 0.59 \\
\hline Total & & & & & & 1853 & 1544 & 680 & 841 & 332 & 2127 & 1579 & 656 & 686 & 202 & 1922 & 1166 & \\
\hline
\end{tabular}

M: male; F: female; HWE: Hardy-Weinberg equilibrium.

Table 2. Characteristics of the studies rs 9340799 polymorphism included in the meta-analysis.

\begin{tabular}{|c|c|c|c|c|c|c|c|c|c|c|c|c|c|c|c|c|c|c|}
\hline \multirow[t]{2}{*}{$\begin{array}{l}\text { First author and } \\
\text { publication year }\end{array}$} & \multirow[t]{2}{*}{ Region } & \multicolumn{2}{|c|}{ Gender (M/F) } & \multicolumn{2}{|c|}{ Mean age (year) } & \multicolumn{2}{|c|}{ Sample size } & \multicolumn{3}{|c|}{$\begin{array}{l}\text { Genotype fre- } \\
\text { quency in cases }\end{array}$} & \multicolumn{2}{|c|}{$\begin{array}{l}\text { Alleles in } \\
\text { cases }\end{array}$} & \multicolumn{3}{|c|}{$\begin{array}{l}\text { Genotype } \\
\text { frequency in } \\
\text { controls }\end{array}$} & \multicolumn{2}{|c|}{$\begin{array}{l}\text { Alleles in } \\
\text { control }\end{array}$} & \multirow[t]{2}{*}{$\begin{array}{l}P \\
\text { HW } \\
\text { E }\end{array}$} \\
\hline & & Cases & Controls & Cases & Controls & Cases & $\begin{array}{l}\text { Con- } \\
\text { trols }\end{array}$ & $\mathrm{AA}$ & AG & GG & A & G & $\mathrm{AA}$ & AG & GG & A & G & \\
\hline Huang, 2002 [31] & Hubei & $81 / 54$ & $50 / 68$ & $\begin{array}{l}\text { No men- } \\
\text { tioned }\end{array}$ & No mentioned & 135 & 118 & 96 & 32 & 7 & 224 & 46 & 83 & 30 & 5 & 196 & 40 & 0.3 \\
\hline Zheng, 2002 [32] & Hebei & $0 / 51$ & $0 / 52$ & $64.2 \pm 9.7$ & $62.05 \pm 7.8$ & 51 & 52 & 3 & 44 & 4 & 50 & 52 & 8 & 42 & 2 & 58 & 46 & 0.12 \\
\hline Cheng, 2006 [33] & Tianjin & $105 / 95$ & 98/92 & $56.5 \pm 0.4$ & $52.4 \pm 0.6$ & 200 & 190 & 147 & 49 & 4 & 343 & 57 & 139 & 49 & 2 & 327 & 53 & 0.31 \\
\hline Li, 2006 [34] & Tianjin & $0 / 165$ & $0 / 80$ & $61.7 \pm 8.2$ & $59.9 \pm 7.7$ & 165 & 80 & 96 & 57 & 12 & 249 & 81 & 40 & 31 & 9 & 111 & 49 & 0.43 \\
\hline $\mathrm{Xu}, 2008$ [19] & $\begin{array}{l}\text { Jiang- } \\
\text { su }\end{array}$ & $94 / 116$ & $89 / 85$ & $56.0 \pm 7.3$ & $55.0 \pm 8.6$ & 210 & 174 & 40 & 57 & 113 & 109 & 283 & 33 & 43 & 98 & 109 & 219 & 0.11 \\
\hline Tang, 2008 [35] & Hubei & $161 / 0$ & $158 / 0$ & $61.4 \pm 8.1$ & $60.9 \pm 6.4$ & 161 & 158 & 66 & 74 & 20 & 206 & 114 & 65 & 73 & 21 & 203 & 115 & 0.15 \\
\hline Jin, 2010 [36] & $\begin{array}{l}\text { Guangd } \\
\text { ong }\end{array}$ & $169 / 67$ & $75 / 42$ & $64.0 \pm 11.0$ & $62.0 \pm 11.0$ & 236 & 117 & 168 & 58 & 10 & 394 & 78 & 83 & 30 & 4 & 196 & 38 & 0.53 \\
\hline Shen, 2012 [37] & $\begin{array}{l}\text { Chong- } \\
\text { qing }\end{array}$ & $289 / 250$ & $286 / 253$ & $57.3 \pm 7.2$ & $56.4 \pm 9.1$ & 539 & 539 & 123 & 258 & 158 & 504 & 572 & 131 & 265 & 143 & 527 & 551 & 0.71 \\
\hline Total & & & & & & 1697 & 1428 & 739 & 629 & 328 & 2079 & 1283 & 582 & 563 & 284 & 1727 & 1111 & \\
\hline
\end{tabular}

M: male; F: female; HWE: Hardy-Weinberg equilibrium.

\section{Association of the ESRI rs2234693 polymor- phism and CHD}

We determined the association the ESR1 rs2234693 polymorphism with CHD risk in ten eligible studies, and total of 1856 cases and 1544 controls were pooled to assess gene effects. There was evidence of between-study heterogeneity under a dominant model (CC + TC allele vs. TT allele: $I^{2}=72 \%, P$ for heterogeneity $=0.0003$ ), additive model (CC allele vs. TT allele: $I^{2}=52 \%, P$ for heterogeneity $\left.=0.03\right)$, co-dominant model (TC allele vs. TT + CC allele: $I^{2}=$ $44 \%, P$ for heterogeneity $=0.06$ ), allelic contrast model (C allele vs. T allele: $I^{2}=77 \%, P$ for heterogeneity $=$ $0.0001)$, respectively. Therefore, a random effect model was used for these genetic models. There was no evidence of between-study heterogeneity under a recessive model (CC allele vs. TC + TT allele: $I^{2}=11 \%$, $P$ for heterogeneity $=0.34$ ), so a fixed effect model was 
used for this genetic model.

We found that the rs2234693 CC allele was associated with an increased the risk of CHD under a dominant model (CC + TC allele vs. TT allele, $P=$ 0.05). The pooled OR was 1.35 (95\% CI: 1.01-1.81) by the random effect model, with between-study heterogeneity $\left(\mathrm{I}^{2}=72 \%, P=0.0003\right)$ (Fig. 2$)$. Similar results could be analysis under a recessive model (CC allele vs. TC + TT allele, OR=1.40, 95\% CI: 1.15-1.69, $P=$ 0.0007 ) and an additive model (CC allele vs. TT allele, OR=1.67, 95\% CI: 1.19-2.34, $P=0.003)$. Nevertheless, under a co-dominant model (TC allele vs. TT + CC allele) and an allele contrast model was no statistically significant association between the rs2234693 polymorphism and CHD on this analysis. Results of overall these studies for meta-analysis are summarized in Table 3.

In the stratified analysis for female, the data on

\begin{tabular}{|c|c|c|c|c|c|c|c|}
\hline Study or Subqroup & $\begin{array}{l}\text { Case } \\
\text { Events }\end{array}$ & Total & $\begin{array}{l}\text { Contr } \\
\text { Events }\end{array}$ & Total & Weight & $\begin{array}{c}\text { Odds Ratio } \\
\text { M-H, Random, } 95 \% \mathrm{Cl}\end{array}$ & $\begin{array}{c}\text { Odds Ratio } \\
\mathrm{M}-\mathrm{H}, \text { Random, } 95 \% \mathrm{Cl}\end{array}$ \\
\hline Cheng, 2006[33] & 135 & 200 & 123 & 190 & $11.8 \%$ & $1.13[0.74,1.72]$ & \\
\hline Guo, 2002[30] & 62 & 72 & 30 & 53 & $6.6 \%$ & $4.75[2.01,11.24]$ & \\
\hline Huang, 2002[31] & 55 & 135 & 67 & 118 & $10.7 \%$ & $0.52[0.32,0.86]$ & \\
\hline Jin, 2010[36] & 152 & 236 & 68 & 117 & $11.3 \%$ & $1.30[0.83,2.05]$ & \\
\hline Li, 2006[34] & 132 & 165 & 59 & 80 & $9.1 \%$ & $1.42[0.76,2.67]$ & \\
\hline Shen, 2012[37] & 294 & 539 & 265 & 539 & $14.1 \%$ & $1.24[0.98,1.58]$ & \\
\hline Tang, 2008[35] & 113 & 161 & 112 & 158 & $10.9 \%$ & $0.97[0.60,1.56]$ & \\
\hline$X u, 2008[19]$ & 118 & 210 & 92 & 174 & $12.0 \%$ & $1.14[0.76,1.71]$ & \\
\hline Zheng, 2002[32] & 42 & 51 & 36 & 54 & $6.1 \%$ & $2.33[0.93,5.83]$ & \\
\hline Zheng, 2001[29] & 70 & 84 & 36 & 61 & $7.5 \%$ & $3.47[1.61,7.48]$ & \\
\hline Total $(95 \% \mathrm{CI})$ & & 1853 & & 1544 & $100.0 \%$ & $1.35[1.01,1.81]$ & \\
\hline Total events & 1173 & & 888 & & & & \\
\hline \multicolumn{7}{|c|}{$\begin{array}{l}\text { Heterogeneity: } \text { Tau }^{2}=0.14 ; \mathrm{Chi}^{2}=31.08, \mathrm{df}=9(P=0.0003) ; I^{2}=71 \% \\
\text { Test for overall effect: } Z=2.00(P=0.05)\end{array}$} & 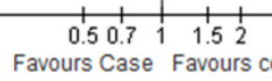 \\
\hline
\end{tabular}

Fig 2. Forest plots of the association of the rs 2234693 polymorphisms with CHD under the dominant model (CC+TC vs. TT). OR (blue squares) and $95 \%$ $\mathrm{Cl}$ are shown for individual study. The summary pooled of ORs and $95 \% \mathrm{Cls}$ are indicated by the black diamond. The word 'Events' in the column headings indicates the total number of CC+TC alleles, and the word 'Total' indicates the total number of the CC+TC alleles plus TT alleles.

Table 3. Main results of pooled odds ratios (ORs) with confidence intervals $(\mathrm{Cl})$ in the meta-analysis for rs 2234693 .

\begin{tabular}{|c|c|c|c|c|}
\hline Allele contrasts in different genetic models & Pool OR (95\% CI) & $\mathrm{P}$-value for $\mathrm{Z}$ test & $\begin{array}{l}\text { I2 for heterogeneity } \\
(\%)\end{array}$ & $\begin{array}{l}\text { P-value for heter- } \\
\text { ogeneity }\end{array}$ \\
\hline \multicolumn{5}{|l|}{ rs2234693 (Overall) } \\
\hline Dominant (CC+TC allele vs. TT allele) & Random effects $1.35(1.01,1.81)$ & 0.05 & 72 & 0.0003 \\
\hline Recessive (CC allele vs. TC + TT allele) & Fixed effects $1.40(1.15,1.69)$ & 0.0007 & 11 & 0.34 \\
\hline Additive (CC allele vs. TT allele) & Random effects $1.67(1.19,2.34)$ & 0.003 & 52 & 0.03 \\
\hline Co-dominant (TC allele vs. TT + CC allele) & Random effects $1.04(0.85,1.27)$ & 0.71 & 44 & 0.06 \\
\hline allele contrast ( $\mathrm{C}$ allele vs. $\mathrm{T}$ allele) & Random effects $1.09(0.88,1.36)$ & 0.43 & 76 & 0.0001 \\
\hline \multicolumn{5}{|l|}{ rs2234693 (Female) } \\
\hline Dominant (CC+TC allele vs. TT allele) & Random effects $0.70(0.41,1.20)$ & 0.20 & 59 & 0.04 \\
\hline Recessive (CC allele vs. TC + TT allele) & Fixed effects $0.82(0.53,1.25)$ & 0.35 & 9 & 0.36 \\
\hline Additive (CC allele vs. TT allele) & Random effects $1.05(1.19,2.34)$ & 0.92 & 65 & 0.02 \\
\hline Co-dominant (TC allele vs. TT + CC allele) & Random effects $1.15(0.69,1.90)$ & 0.60 & 57 & 0.05 \\
\hline allele contrast (C allele vs. T allele) & Random effects $170(0.98,2.94)$ & 0.47 & 66 & 0.02 \\
\hline \multicolumn{5}{|l|}{ rs2234693 (Male) } \\
\hline Dominant (CC+TC allele vs. TT allele) & Random effects $1.22(0.71,2.11)$ & 0.47 & 66 & 0.03 \\
\hline Recessive (CC allele vs. TC + TT allele) & Fixed effects $1.62(1.10,2.39)$ & 0.01 & 34 & 0.21 \\
\hline Additive (CC allele vs. TT allele) & Random effects $1.94(0.93,4.03)$ & 0.08 & 57 & 0.07 \\
\hline Co-dominant (TC allele vs. TT + CC allele) & Fixed effects $0.86(0.65,1.16)$ & 0.32 & 10 & 0.34 \\
\hline allele contrast (C allele vs. T allele) & Random effects $1.29(0.88,1.90)$ & 0.20 & 67 & 0.03 \\
\hline
\end{tabular}

genotypes of the rs2234693 polymorphism among female population cases and controls were available in 5 studies (including 400 cases and 300 controls) [19, $29,31,32,34]$. We didn't found that the rs2234693 were significant associated with CHD risk under all genetic models. Results of the stratified analysis studies on female are summarized in Table 3. For male, the data on genotypes of the rs 2334693 polymorphism among male population cases and controls were available in 4 studies (including 406 cases and 345 controls) $[19,29,31,35]$. We found that the rs2234693 CC allele was associated with an increased the risk of CHD under a recessive model (CC allele vs. TT allele, $P=0.01$ ), and under other genetic models are no significant associated between CHD risk. Results of the stratified analysis studies for male are summarized in Table 3.

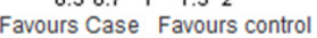




\section{Association of the ESRI rs9340799 polymor- phism and CHD}

We determined the association ESR1 rs9340799 polymorphism with CHD risk in eight eligible studies, and total of 1696 cases and 1429 controls were pooled to assess gene effects. There was no evidence of between-study heterogeneity under a dominant model (GG + AG allele vs. AA allele: $I^{2}=0 \%, P$ for heterogeneity $=0.79)$, recessive model (GG allele vs. AG + AA allele: $I^{2}=0 \%, P$ for heterogeneity $\left.=0.82\right)$, additive model (GG allele vs. AA allele: $I^{2}=0 \%, P$ for heterogeneity $=0.64)$, co-dominant model (AG allele vs. AA + GG allele: $I^{2}=0 \%, P$ for heterogeneity $=$ $0.99)$, allelic contrast model (G allele vs. A allele: $I^{2}=$ $0 \%, P$ for heterogeneity $=0.62)$, respectively. Therefore, a fixed-effects model was used for these genetic models. And the results of meta-analysis for overall these studies are summarized in Table 4 . We did not detect any significant association of rs9340799 polymorphism with CHD risk under a dominant model

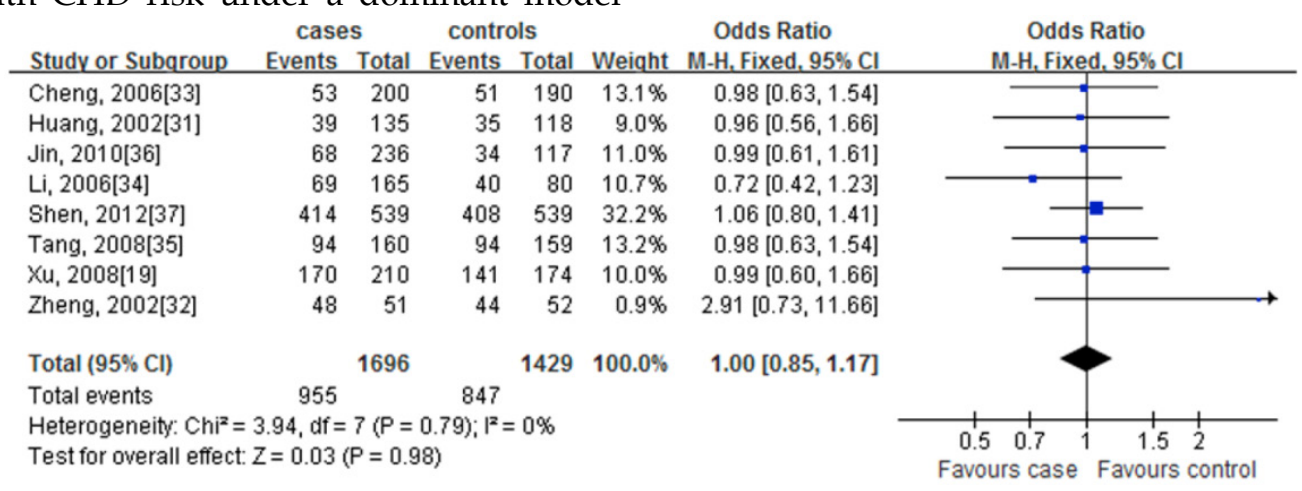

Fig 3. Forest plots of the association of the rs 9340799 polymorphism with coronary heart disease under the dominant model (GG+AG vs. AA). OR (blue squares) and $95 \% \mathrm{Cl}$ are shown for individual study. The summary pooled of ORs and $95 \% \mathrm{Cls}$ are indicated by the black diamond. The word 'Events' in the column headings indicates the total number of GG+AG alleles, and the word 'Total' indicates the total number of the GG+AG alleles plus AA alleles.

Table 4. Main results of pooled odds ratios (ORs) with confidence intervals (Cl) in the meta-analysis for rs 9340799 .

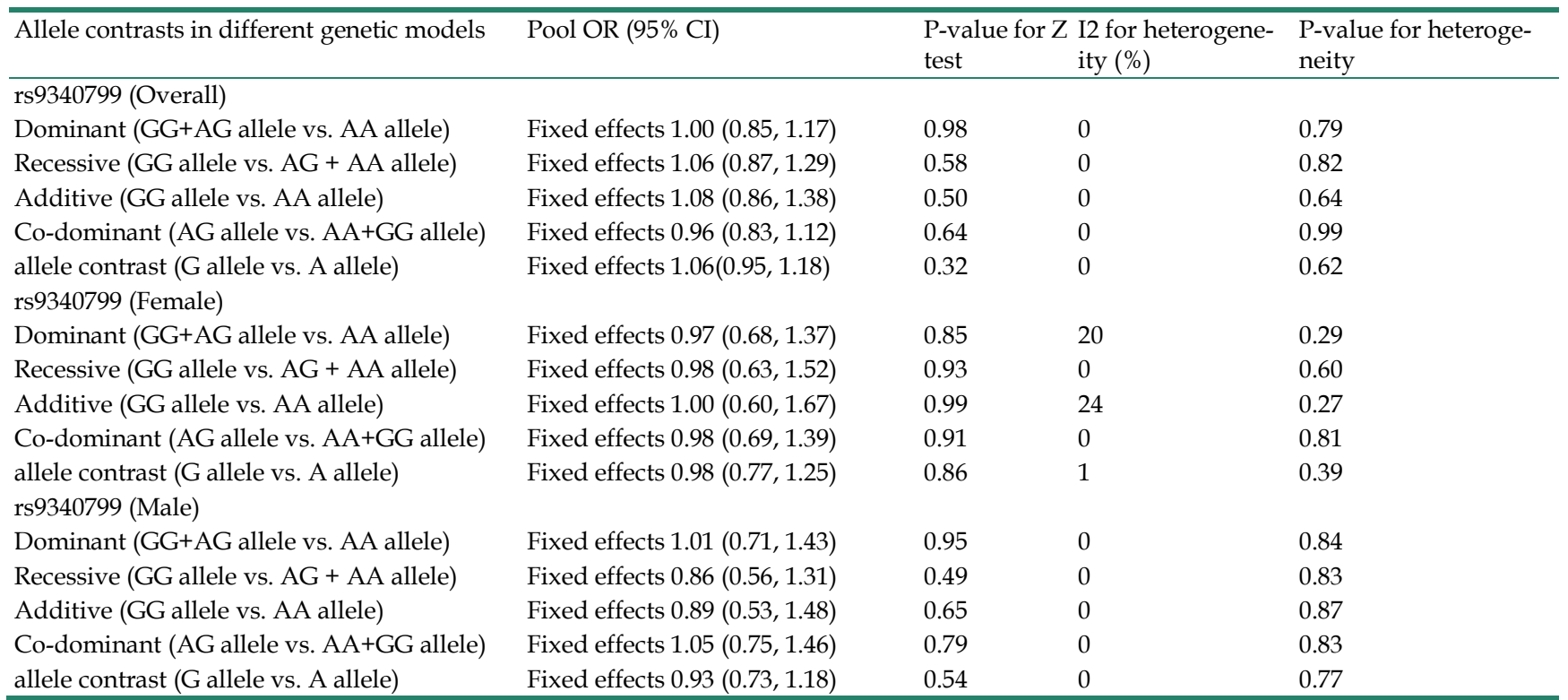

(GG + AG allele vs. AA allele, $P=0.98)$ (Fig. 3), without statistically significant heterogeneity among studies $\left(I^{2}=0 \%, P=0.79\right)$. Results of meta-analysis were similar in other genetic models.

In the stratified analysis for female, the data on genotypes of the rs9340799 polymorphism among female population cases and controls were available in 4 studies (including 388 cases and 285 controls) [19, $31,32,34]$. We found that no significant association between the rs9340799 polymorphism and CHD risk under all genetic models. Results of the stratified analysis studies on female are summarized in Table 4. For male, the data on genotypes of the rs9340799 polymorphism among male population cases and controls were available in 3 studies (including 335 cases and 298 controls) $[19,31,35]$. We also found that no significant association between the rs9340799 polymorphism and CHD risk under all genetic models. Results of the stratified analysis studies on male are summarized in Table 4.

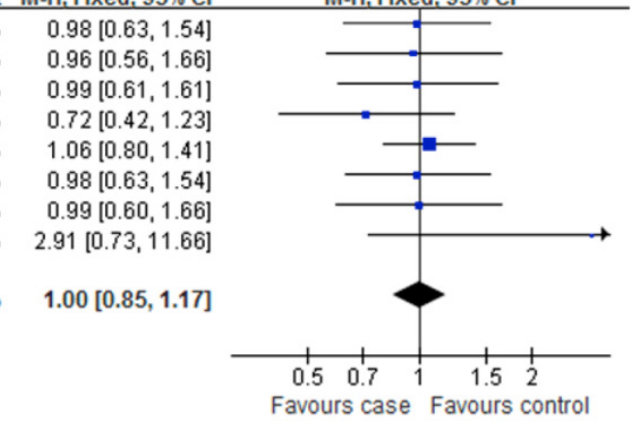




\section{Sensitivity analysis}

Sensitivity analysis was performed by excluding one study at a time and calculating the pooled ORs for the remaining studies. This procedure was used to ensure that no individual study was entirely responsible for the combined analysis results. The pooled ORs are listed in Table 5. Sensitivity analysis indicated that the results of the meta-analysis on association of ESR1 rs2234693 and rs9340799 polymorphisms with CHD risk were reliable and stable.

\section{Potential publication bias}

Publication bias was qualitatively examined using the funnel plots and quantitatively estimated by Begg's test and Egger's test based on dominant genetic model data. The funnel plots were symmetrical by visual inspection. Including in this meta-analysis, there are two PhD theses [29, 32], so publication bias test did not including them. The funnel plots have been shown that the rs2234693 (Fig. 4 A) and the rs9340799 (Fig. 4 B) are no evidence of publication bias. The results of Egger's test also indicated that the rs2234693 ( $P=0.198,95 \% \mathrm{CI}:-1.3145,5.1117)$ and the rs9340799 ( $P=0.133,95 \%$ CI: $-27.8016,4.9592)$ are no evidence of publication bias.
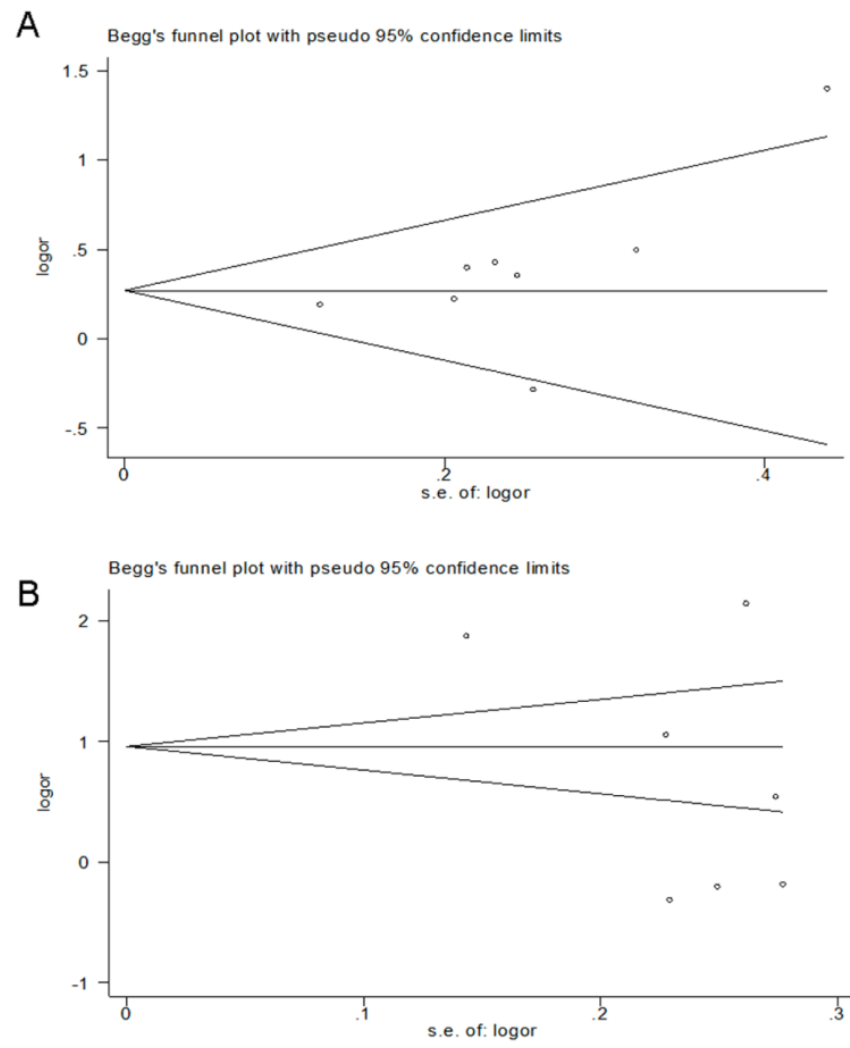

Fig 4. Funnel plots of rs 2234693 for a dominant model (CC+TC vs. TT) (A) and rs 9340799 for a dominant model (GG+AG vs. AA) (B). SE standard error.

Table 5. Sensitivity analysis of the ESRI rs2234693 and rs 9340799 polymorphisms and CHD under an additive model.

\begin{tabular}{|c|c|c|c|c|c|c|}
\hline $\begin{array}{l}\text { Excluded study } \\
\text { characteristic }\end{array}$ & included studies & Excluded studies & Pooled ORs (95\%) & $P$-value & $\mathrm{I}^{2}(\%)$ & $\begin{array}{l}P \text {-value for } \\
\text { heterogeneity }\end{array}$ \\
\hline \multicolumn{7}{|l|}{ rs2234693 } \\
\hline & $19,29-37$ & none & Random effects $1.67(1.19,2.34)$ & 0.003 & 52 & 0.03 \\
\hline & $19,29-36$ & 37 & Random effects $1.72(1.14,2.60)$ & 0.009 & 58 & 0.02 \\
\hline & $19,29-35,37$ & 36 & Random effects $1.60(1.12,2.30)$ & 0.01 & 54 & 0.03 \\
\hline & $19,29-34,36,37$ & 35 & Random effects $1.79(1.24,2.58)$ & 0.002 & 54 & 0.03 \\
\hline & $29-37$ & 19 & Random effects $1.66(1.14,2.42)$ & 0.008 & 57 & 0.02 \\
\hline & $19,29-33,35-37$ & 34 & Random effects $1.75(1.21,2.54)$ & 0.003 & 57 & 0.02 \\
\hline & $19,29-32,34-37$ & 33 & Random effects $1.78(1.22,2.60)$ & 0.003 & 55 & 0.02 \\
\hline & $19,29-31,33-37$ & 32 & Random effects $1.65(1.16,2.36)$ & 0.006 & 52 & 0.02 \\
\hline & $19,29,30,32-37$ & 31 & Random effects $1.80(1.30,2.51)$ & 0.0004 & 52 & 0.06 \\
\hline & $19,29,31-37$ & 30 & Random effects $1.51(1.13,2.02)$ & 0.006 & 52 & 0.08 \\
\hline & $19,30-37$ & 29 & Random effects $1.54(1.12,2.13)$ & 0.009 & 52 & 0.06 \\
\hline \multicolumn{7}{|l|}{ rs9340799 } \\
\hline & $19,31-37$ & none & Fixed effects $1.08(0.86,1.38)$ & 0.5 & 0 & 0.64 \\
\hline & $19,31-36$ & 37 & Fixed effects $1.00(0.71,1.40)$ & 0.99 & 0 & 0.59 \\
\hline & $19,31-35,37$ & 36 & Fixed effects $1.08(0.85,1.37)$ & 0.54 & 0 & 0.53 \\
\hline & $19,31-34,36,37$ & 35 & Fixed effects $1.11(0.86,1.42)$ & 0.78 & 0 & 0.55 \\
\hline & $31-37$ & 19 & Fixed effects $1.12(0.86,1.46)$ & 0.4 & 0 & 0.56 \\
\hline & $19,31-33,35-37$ & 34 & Fixed effects $1.13(0.89,1.45)$ & 0.32 & 0 & 0.80 \\
\hline & $19,31,32,34-37$ & 33 & Fixed effects $1.07(0.84,1.36)$ & 0.57 & 0 & 0.58 \\
\hline & $19,31,33-37$ & 32 & Fixed effects $1.06(0.84,1.35)$ & 0.62 & 0 & 0.81 \\
\hline & $19,32-37$ & 31 & Fixed effects $1.08(0.85,1.38)$ & 0.54 & 0 & 0.53 \\
\hline
\end{tabular}

OR: odds ratio; CI: confidence interval. 


\section{Discussion}

Human ESR1 gene is located on chromosome 6q25.1, wild-type ESR1 gene length of $140 \mathrm{~kb}$, and consists of eight exons separated by seven introns. Study indicated that the ESR1 is a major mediator of the atheroprotective effect of estrogen on animal and human [38]. When ERs bind to estrogen, a conformational change ensues that enables the homodimerization of the complex, allowing for binding to estrogen response elements and subsequently altering the expression of relevant target genes, And the result that thereby regulating the growth, reproduction, differentiation and function of many target organs, including the breast tissue, cardiovascular system, nervous system, bone tissue, liver, and so on. As cardiovascular disease, various studies have focused on the ESR1 rs2234693 and rs9340799 polymorphisms with risk of CHD. However, the results were inconclusive. According to Chinese Han population, previous studies [29-31, 35-37] indicated that the ESR1 rs2234693 polymorphism was significantly associated with CHD risk. However, another studies [19, 32-34] found that the ESR1 rs2234693 polymorphism was not significantly associated with CHD risk. Those conflicting results indicated that a meta-analysis should be performed to determine whether the ESR1 gene rs2234693 polymorphism was associated with CHD risk in Chinese Han population.

In the present meta-analysis, our results demonstrated that the ESR1 rs2234693 polymorphism is associated with increased the risk of CHD under a Dominant, Recessive and Additive genetic model. There are not statistically significant association of the rs2234693 polymorphism with CHD risk was detected under a co-dominant and an allele contrast model. And no significant of the allele contrast model explained that only those people have the homozygous mutant would increase the risk CHD. Subgroup for male results showed that ESR1 gene rs2234693 CC genotype could increase the risk of CHD compared with TT genotype and TC genotype in Chinese Han population. However, we found no strong statistical evidence of associations between rs2234693 polymorphism and CHD risk on subgroup for female. In the circulation, the level of estrogen in males is lower than premenopausal females. Estrogen exerts their effects through banding and activating estrogen receptors (ERs), and ESR1 is a main mediator effect of estrogen. The mutation of ESR1 gene might influence the expression of ESR1 and affect the function of estrogen on CHD $[15,16]$. It is illustrated why that the mutation of ESR1 gene is increased risk of CHD in males. Egger's test for ESR1 gene rs2234693 poly- morphism indicated that was not publication bias $(P=$ $0.189)$, sensitivity analysis also indicated that no single study influenced the pooled OR qualitatively for the ESR1 gene rs2234693 polymorphism with CHD risk for a dominant model. Taken together, these data further confirm the reliability and stability of the meta-analysis results.

Previous studies in Framingham Offspring [39] and Finnish [40] indicated that the CC versus TT genotype was association with CHD risk in men. However, in the Rotterdam study shown that the TT versus $C$ C genotype was association with $C H D$ risk in women but not in men [41]. A large sample of European descent in cases-controls [42], Danish individuals followed for 23-25 years [43], and British Women studies [20] indicated that the ESR1 gene rs2234693 polymorphism is not significant associated with CHD risk. And a recent meta-analysis in overall populations indicated that the ESR1 rs2234693 polymorphism is lack of association between and CHD in men and women [44]. Furthermore, the ESR1 polymorphism could have a very different effect in the male and female, effects that even could differ between different contexts in different countries. Nevertheless, our results indicated that the ESR1 rs2234693 CC genotype is association between with increasing CHD risk in men of Chinese Han population, but not in women.

Regarding the ESR1 gene rs9340799 mutation, overall (male and female) or subgroup on male and female, the results of meta-analysis demonstrated that ESR1 gene rs9340799 polymorphism was no significant association with CHD risk under different genetic models in Chinese Han population. These results of meta-analysis were consistent with the previous studies in Chinese Han population and other populations.

Several limitations should be noted in this meta-analysis. Firstly, the effect of gene-gene and gene-environment interaction was not evaluation, and the coronary heart disease has a complex aetiology generated by the combined effect of genetic and environmental risk factors. Secondly, we did not perform analysis for haplotype. Although one of article [31] including in this meta-analysis indicated that the linkage disequilibrium between SNPs in ESR1 rs2234693 and rs9340799 is no significant association with increasing the risk of CHD. However, other research indicated that haplotype was associated with past and current use of hormone replacement and with those women with one or two copies of the T-A haplotype being more likely to have used hormone replacement than those who did not carry the haplotype [20]. Therefore, the different linkage disequilib- 
rium (LD) pattern of these potential functional SNPs with rs2234693 in different ethnic populations may explain the different associations between rs2234693 and CHD risk. Therefore, genetic backgrounds might explain, to some extent, the somewhat conflicting associations in different populations. Thirdly, only 10 studies were included in our meta-analysis. And a small number of studies and sample size limited the ability to draw more solid conclusions.

In conclusion, in present meta-analysis results demonstrated that the ESR1 rs2234693 CC genotype is significantly associated with increased risk of CHD in male, but no evidence associated with CHD risk in female in Chinese Han population. No evidence of significant association with CHD risk was found for the ESR1 rs9340799 mutation. However, more well-designed large studies are required for the association of the ESR1 gene polymorphisms with CHD risk.

\section{Acknowledgments}

This work was supported by grants from the National Natural Science Foundation of China (NO: 81100959) and National Clinical Key Specialty Construction Projects.

\section{Conflicts of interest}

We declare that we have no conflicts of interest.

\section{References}

1. Negi S, Anand A. Atherosclerotic coronary heart disease-epidemiology, classification and management. Cardiovascular \& hematological disorders drug targets. 2010; 10: 257-61.

2. Mi X, Eskridge KM, George V, et al. Structural equation modeling of gene-environment interactions in coronary heart disease. Annals of human genetics. 2011; 75: 255-65.

3. Isles CG, Hole DJ, Hawthorne VM, et al. Relation between coronary risk and coronary mortality in women of the Renfrew and Paisley survey: comparison with men. Lancet. 1992; 339: 702-6.

4. Gurevitz O, Jonas M, Boyko V, et al. Clinical profile and long-term prognosis of women $<$ or $=50$ years of age referred for coronary angiography for evaluation of chest pain. The American journal of cardiology. 2000; 85: 806-9.

5. Stampfer MJ, Colditz GA. Estrogen replacement therapy and coronary heart disease: a quantitative assessment of the epidemiologic evidence. Preventive medicine. 1991; 20: 47-63.

6. Konukoglu D, Serin O, Ercan M. The relationship between plasma viscosity and cholesterol in postmenopausal women on hormone replacement therapy. Clinical hemorheology and microcirculation. 2000; 22: 223-8.

7. Burns KA, Korach KS. Estrogen receptors and human disease: an update. Archives of toxicology. 2012; 86: 1491-504.

8. Mangelsdorf DJ, Thummel C, Beato $\mathrm{M}$, et al. The nuclear receptor superfamily: the second decade. Cell. 1995; 83: 835-9.

9. Hewitt SC, O'Brien JE, Jameson JL, et al. Selective disruption of ER\{alpha\} DNA-binding activity alters uterine responsiveness to estradiol. Mol Endocrinol. 2009; 23: 2111-6.

10. Burns KA, Li Y, Arao Y, et al. Selective mutations in estrogen receptor alpha D-domain alters nuclear translocation and non-estrogen response element gene regulatory mechanisms. The Journal of biological chemistry. 2011; 286: 12640-9.

11. Losordo DW, Kearney M, Kim EA, et al. Variable expression of the estrogen receptor in normal and atherosclerotic coronary arteries of premenopausal women. Circulation. 1994; 89: 1501-10.
12. Pare G, Krust A, Karas RH, et al. Estrogen receptor-alpha mediates the protective effects of estrogen against vascular injury. Circulation research. 2002; 90: 1087-92.

13. Booth EA, Obeid NR, Lucchesi BR. Activation of estrogen receptor-alpha protects the in vivo rabbit heart from ischemia-reperfusion injury. American journal of physiology Heart and circulatory physiology. 2005; 289: H2039-47.

14. Zhai P, Eurell TE, Cooke PS, et al. Myocardial ischemia-reperfusion injury in estrogen receptor-alpha knockout and wild-type mice. American journal of physiology Heart and circulatory physiology. 2000; 278: H1640-7.

15. Herrington DM, Howard TD, Brosnihan KB, et al. Common estrogen receptor polymorphism augments effects of hormone replacement therapy on E-selectin but not C-reactive protein. Circulation. 2002; 105: 1879-82.

16. Nordstrom P, Glader CA, Dahlen G, et al. Oestrogen receptor alpha gene polymorphism is related to aortic valve sclerosis in postmenopausal women. Journal of internal medicine. 2003; 254: 140-6.

17. Mansur Ade P, Nogueira CC, Strunz CM, et al. Genetic polymorphisms of estrogen receptors in patients with premature coronary artery disease. Archives of medical research. 2005; 36: 511-7.

18. Boroumand M, Ghaedi M, Mohammadtaghvaei N, et al. Association of estrogen receptor alpha gene polymorphism with the presence of coronary artery disease documented by coronary angiography. Clinical biochemistry. 2009; 42: 835-9.

19. Xu H, Hou X, Wang N, et al. Gender-specific effect of estrogen receptor-1 gene polymorphisms in coronary artery disease and its angiographic severity in Chinese population. Clinica chimica acta, international journal of clinical chemistry. 2008; 395: 130-3.

20. Lawlor DA, Timpson N, Ebrahim S, et al. The association of oestrogen receptor alpha-haplotypes with cardiovascular risk factors in the British Women's Heart and Health Study. European heart journal. 2006; 27: 1597-604.

21. Stroup DF, Berlin JA, Morton SC, et al. Meta-analysis of observational studies in epidemiology: a proposal for reporting. Meta-analysis $\mathrm{Of} \mathrm{Ob}-$ servational Studies in Epidemiology (MOOSE) group. JAMA : the journal of the American Medical Association. 2000; 283: 2008-12.

22. Tunstall-Pedoe H, Kuulasmaa K, Amouyel $\mathrm{P}$, et al. Myocardial infarction and coronary deaths in the World Health Organization MONICA Project. Registration procedures, event rates, and case-fatality rates in 38 populations from 21 countries in four continents. Circulation. 1994; 90: 583-612.

23. Thakkinstian A, McElduff P, D'Este C, et al. A method for meta-analysis of molecular association studies. Statistics in medicine. 2005; 24 : 1291-306.

24. Higgins JP, Thompson SG, Deeks JJ, et al. Measuring inconsistency in meta-analyses. BMJ. 2003; 327: 557-60.

25. Higgins JP, Thompson SG. Quantifying heterogeneity in a meta-analysis. Statistics in medicine. 2002; 21: 1539-58.

26. Lau J, Ioannidis JP, Schmid CH. Quantitative synthesis in systematic reviews. Annals of internal medicine. 1997; 127: 820-6.

27. Begg CB, Mazumdar M. Operating characteristics of a rank correlation test for publication bias. Biometrics. 1994; 50: 1088-101.

28. Egger M, Davey Smith G, Schneider M, et al. Bias in meta-analysis detected by a simple, graphical test. BMJ. 1997; 315: 629-34.

29. Zheng $H$. Relationship between estrogen receptor gene polymorphism and coronary heart disease. PhD thesis, The first military medical university. 2001.

30. Guo ZG, Zheng H, Wu SZ, et al. Relatioonship between estrogen receptor gene polymorphism and coronary heart disease. Chinese Journal of Geriatric Heart Brain and Vessel Diseases. 2002; 4: 374-7.

31. Huang $X Z$, Zhang PA, Li Y, et al. Association of estrogen receptor gene polymorphisms with coronary heart disease. Chinese Journal of Cardiology. 2002; 30: 78-81.

32. Zheng HM. The study about the association between the polymorphisms of the estrogen receptor and coronary artery disease or the lipoprotein metabolism in women. PhD thesis, Hebei Medical University. 2002.

33. Cheng AJ, Fu NK, Xu J, et al. A study of the correlation between estrogen receptor gene polymorphism and coronary heart disease as well as serum lipid levels in postmenopausal women. Hebei Medical Journal (China). 2006; 28: 568-70.

34. Li LH, Zhao FM, Li GQ, et al. Association between estrogen receptor alpha gene variation and risk of cardiovascular disease. Molecular Cardiology of China. 2006; 6: 90-4.

35. Tang ZZ, Li XP, Yang JH, et al. Relationship of estrogen receptor a gene polymorphism and risk of cardiovascular disease. Military Medical Journal of South China. 2008; 22: 35-7. 
36. Jin LZ, Chen XC, Ma YD, et al. Association of estrogen receptor a gene $\mathrm{Pvu}$ II and Xba I polymorphisms with coronary artery disease. Chinese Journal of Biomedical Engineering. 2010; 16: 136-9.

37. Shen C, Chen J, Fan S, et al. Association between the polymorphism of estrogen receptor alpha and coronary artery disease in a Chinese population. European journal of internal medicine. 2012; 23: 175-8.

38. Hodgin JB, Krege JH, Reddick RL, et al. Estrogen receptor alpha is a major mediator of 17beta-estradiol's atheroprotective effects on lesion size in Apoe-/- mice. The Journal of clinical investigation. 2001; 107: 333-40.

39. Shearman AM, Cupples LA, Demissie S, et al. Association between estrogen receptor alpha gene variation and cardiovascular disease. JAMA : the journal of the American Medical Association. 2003; 290: 2263-70.

40. Lehtimaki T, Kunnas TA, Mattila KM, et al. Coronary artery wall atherosclerosis in relation to the estrogen receptor 1 gene polymorphism: an autopsy study. J Mol Med (Berl). 2002; 80: 176-80.

41. Schuit SC, Oei HH, Witteman JC, et al. Estrogen receptor alpha gene polymorphisms and risk of myocardial infarction. JAMA : the journal of the American Medical Association. 2004; 291: 2969-77.

42. Koch W, Hoppmann P, Pfeufer A, et al. No replication of association between estrogen receptor alpha gene polymorphisms and susceptibility to myocardial infarction in a large sample of patients of European descent. Circulation. 2005; 112: 2138-42.

43. Kjaergaard AD, Ellervik C, Tybjaerg-Hansen A, et al. Estrogen receptor alpha polymorphism and risk of cardiovascular disease, cancer, and hip fracture: cross-sectional, cohort, and case-control studies and a meta-analysis. Circulation. 2007; 115: 861-71.

44. Lluis-Ganella C, Lucas G, Subirana I, et al. Qualitative assessment of previous evidence and an updated meta-analysis confirms lack of association between the ESR1 rs2234693 (PvuII) variant and coronary heart disease in men and women. Atherosclerosis. 2009; 207: 480-6. 